\title{
Preoperative JJ stent placement in ureteric and renal stone treatment: results from the Clinical Research Office of Endourological Society (CROES) ureteroscopy (URS) Global Study
}

\author{
Dean Assimos, Alfonso Crisci*, Daniel Culkin ${ }^{\dagger}$, Wei Xue $^{\ddagger}$, Anita Roelofs $\$$, Mordechai \\ Duvdevani", Mahesh Desai** and Jean de la Rosette ${ }^{\dagger \dagger}$ on behalf of the CROES URS \\ Global Study Group
}

Department of Urology, University of Alabama at Birmingham School of Medicine, Birmingham, AL, USA, *Department of Urology, Careggi Hospital, Florence, Italy, ${ }^{\dagger}$ Department of Urology, The University of Oklahoma Health Sciences Center, Oklahoma City, OK, USA, ${ }^{\ddagger}$ Department of Urology, Renji Hospital, Shanghai, China, ${ }^{\S}$ Department of Urology, Rijnstate Hospital, Arnhem, The Netherlands, "'Department of Urology, AMC University Medical Centre, Amsterdam, The Netherlands, "Department of Urology, Hadassah Ein-Kerem University Hospital, Jerusalem, Israel, and * Department of Urology, Muljibhai Patel Urological Hospital, Nadiad, India

\section{Objective}

To compare outcomes of ureteric and renal stone treatment with ureteroscopy (URS) in patients with or without the placement of a preoperative JJ stent.

\section{Patients and Methods}

The Clinical Research Office of the Endourological Society (CROES) URS Global Study collected prospective data for 1 year on consecutive patients with ureteric or renal stones treated with URS at 114 centres around the world. Patients that had had preoperative JJ stent placement were compared with those that did not. Inverse-probability-weighted regression adjustment (IPWRA) was used to examine the effect of preoperative JJ stent placement on the stone-free rate (SFR), length of hospital stay (LOHS), operative duration, and complications (rate and severity).

\section{Results}

Of 8189 patients with ureteric stones, there were 978 (11.9\%) and 7133 patients with and without a preoperative JJ stent, respectively. Of the 1622 patients with renal stones, 590 (36.4\%) had preoperative stenting and 1002 did not. For renal stone treatment, preoperative stent placement increased the SFR and operative time, and there was a borderline significant decrease in intraoperative complications. For ureteric stone treatment, preoperative stent placement was associated with longer operative duration and decreased LOHS, but there was no difference in the SFR and complications. One major limitation of the study was that the reason for JJ stent placement was not identified preoperatively.

\section{Conclusions}

The placement of a preoperative JJ stent increases SFRs and decreases complications in patients with renal stones but not in those with ureteric stones.

\section{Keywords}

ureteroscopy, ureteric stones, renal stones, treatment outcome, complications, preoperative JJ stent

\section{Introduction}

The management of patients harbouring ureteric and renal stones with ureteroscopy (URS) has improved considerably over the past two decades. This has been fostered by the introduction of smaller flexible and semi-rigid ureteroscopes, novel grasping devices, baskets and access sheaths, and more effective lasers[1,2]. The European Association of Urology
(EAU) guidelines on urolithiasis now recommend that in those patients without specific contraindications, such as untreated UTIs, URS can be generally applied [3].

Ureteric stents are most commonly placed before ureteroscopic stone removal when there is infection, compromised renal function, when ureteric anatomy does not permit satisfactory introduction of the ureteroscope, or when 
the surgeon desires to perform the procedure in an elective setting. Their successful use in passive ureteric dilatation before URS in a paediatric population has been reported [4]. The EAU guidelines state that routine preoperative stenting before URS for ureteric or renal stones is not necessary [3]; however, several studies report that stone-free rates (SFRs) and complications are improved with preoperative stent use in URS in adults [5-8]. The URS Global Study was conducted by the Clinical Research Office of the Endourology Society (CROES) to establish a prospective global database that could examine the use of URS worldwide, as well as to study what factors affected outcomes. Therefore, the present study describes the current use of preoperative ureteric stenting in conjunction with URS for ureteric and renal stones.

The present study compares the outcomes of patients treated with or without the use of a preoperative JJ stent in order to address the questions of whether a preoperative stent can decrease the intra- and postoperative complication rate and/ or severity, accelerate recovery, and increase SFRs.

\section{Patients and Methods}

\section{Study protocol}

The URS Global Study was a prospective, observational, multicentre, international study, during which data were collected on consecutive patients treated with URS during a 1-year period at each of the centres. The study was conducted from January 2010 through October 2012. All participating centres obtained Institutional Review Board (IRB), or Institutional Ethics Committee approval before the start of the study. In centres where IRB approval was not required, the protocol followed accorded with the rules of Good Clinical Practice.

\section{Study population}

Included in the study were patients who were candidates for URS for ureteric (treated with semi-rigid URS) or renal (treated with flexible URS) stones as a primary treatment or after failure of a previous treatment and aged $\geq 18$ years. Treatment for ureteric stones with flexible URS and renal stones with semirigid URS are not very common, and therefore excluded from the current analyses. There were no further exclusion criteria. In the case that a patient is treated for both a ureteric and renal stone at the same time, the patient is classified as 'renal treatment'. If a patient is retreated, the second procedure is entered in the database as a new case. Further information on the treatment conducted including secondary treatment and patient follow-up have been previously reported [9].

\section{Data collection}

Encrypted data were collected electronically through the website: www.croesoffice.org, and then held at the CROES office in a central database.
The data collected included patient epidemiological and calculus characteristics, treatment details such as type of URS, length of hospital patient stay (LOHS), postoperative outcomes, and complications (bleeding, fever, UTI, pulmonary embolism, deep venous thrombosis, sepsis, acute myocardial infarction, and other complications). Centres were requested to treat patients in accordance with local protocols. Treatment failure was defined as the presence of a part of the treated stone of $>1 \mathrm{~mm}$, failure to access a stone still in situ in the treated area, or large remaining stone fragments requiring additional treatment. A patient free of stones of $>1 \mathrm{~mm}$ in the treated area was classed as a treatment success.

\section{Statistical analysis}

All analyses were performed and are presented separately for the two groups of patients. The first group consists of patients in which a semi-rigid scope was used for removal of ureteric stones and the second group consists of patients in which a flexible scope was used for removal of renal stones. The descriptive information is presented as mean (SD) or median (interquartile range, IQR), for normally distributed and skewed continuous variables, respectively. Dichotomous and categorical variables are presented as actual numbers and as percentages of the total population.

To examine the relationship of preoperative JJ stent placement on the SFR, LOHS (in days), operative duration, and complications (rate and severity), inverse-probability-weighted regression adjustment (IPWRA) was used. Patients are first weighted on baseline characteristics [patient characteristics: body mass index (BMI), gender, age, comorbidity, American Society of Anaesthesiologists (ASA) score], stone characteristics (stone localisation, stone size), academic hospital or not, location and case volume of the hospital. Secondly, crude IPWRA models (only one central determinant: preoperative stent placement) were created for five models with SFR, operative duration, intraoperative complications, postoperative complications, and LOHS as the outcome. Lastly, crude IPWRA models were corrected for all clinically possible confounders (operative duration, LOHS, type of URS, type of evaluation, type of fragmentation device, intraoperative complications, postoperative complications, re-admission, retreatment, LOHS, and nephron-drain placement). All statistical analyses were performed using STATA version 13 (StataCorp LP, College Station, Texas, USA).

\section{Results}

Table 1 shows the characteristics of patients with ureteric stones treated either with or without the use of a preoperative $\mathrm{JJ}$ stent. Of the 8189 patients with ureteric stones who were treated with semi-rigid URS, 1038 (12.7\%) had a preoperative stent, of which 978 were with a JJ stent; 60 
Table 1 Characteristics of patients treated with semi-rigid URS for ureteric stones either with or without the use of a preoperative JJ stent. Number of patients $(n)$ for whom data were available indicated.

\begin{tabular}{|c|c|c|}
\hline Variable & $\begin{array}{l}\text { Patients with JJ } \\
\text { stent }(n=978)\end{array}$ & $\begin{array}{c}\text { Patients without } \\
\text { JJ stent }(n=7 \text { 133) }\end{array}$ \\
\hline \multicolumn{3}{|l|}{ Mean (SD) } \\
\hline Age, years & $52.0(15.8) ; n=978$ & $48.0(15.0) ; n=7133$ \\
\hline BMI, $\mathrm{kg} / \mathrm{m}^{2}$ & $27.3(5.1) ; n=779$ & $26.5(4.5) ; n=5999$ \\
\hline \multicolumn{3}{|l|}{$n / N(\%)$} \\
\hline Female & $313 / 978(32.0)$ & $2417 / 7128(33.9)$ \\
\hline \multicolumn{3}{|l|}{ Co-morbidity, $n$ (\%) } \\
\hline $\mathrm{DM}$ & $111 / 967(11.5)$ & $674 / 7096(9.5)$ \\
\hline CVD & $303 / 960(31.6)$ & $1551 / 7087$ (21.9) \\
\hline Prednisone & $8 / 964(0.8)$ & $47 / 7093(0.7)$ \\
\hline Crohn's disease & 9/964 (0.9) & $16 / 7094(0.2)$ \\
\hline Anticoagulation & $69 / 962(7.2)$ & $286 / 7097(4.0)$ \\
\hline \multicolumn{3}{|l|}{ ASA score } \\
\hline I & $374 / 864(43.3)$ & 4 201/6 800 (61.8) \\
\hline II & $386 / 864(44.7)$ & 2 135/6 $800(31.4)$ \\
\hline III & $100 / 864(11.6)$ & $442 / 6800(6.5)$ \\
\hline IV & $4 / 864(0.5)$ & $22 / 6800(0.3)$ \\
\hline Academic centre & $550 / 978(56.2)$ & $4523 / 7133(63.4)$ \\
\hline $\begin{array}{l}\text { High case-volume } \\
\text { centre }^{*}, n(\%)\end{array}$ & $759 / 978(77.6)$ & 6 053/7 133 (84.9) \\
\hline \multicolumn{3}{|l|}{ Stone location } \\
\hline proximal & $283 / 963(29.4)$ & $1787 / 7078(25.2)$ \\
\hline mid & $237 / 963(24.6)$ & $1440 / 7078(20.3)$ \\
\hline distal & $390 / 963(40.5)$ & $3580 / 7078(50.6)$ \\
\hline multiple & $53 / 963(5.5)$ & $271 / 7078(3.8)$ \\
\hline \multicolumn{3}{|l|}{ Stone size } \\
\hline$\leq 10 \mathrm{~mm}$ & $812 / 978(83.0)$ & 5 095/7 $133(71.4)$ \\
\hline$>10 \mathrm{~mm}$ & $166 / 978(17.0)$ & $2038 / 7133(28.6)$ \\
\hline $\begin{array}{l}\text { Postoperative } \\
\text { nephron-drain }\end{array}$ & 11/977 (1.1) & $139 / 7130(1.9)$ \\
\hline
\end{tabular}

DM, diabetes mellitus; CVD, cardiovascular disease; ${ }^{*}$ Defined as $>67$ cases/year.

patients received another type of stent, and data were not available for 18 patients in the total cohort.

Table 2 shows the characteristics of patients with renal stones who were treated with or without the use of a preoperative JJ stent. Of the 1622 patients with renal stones who were treated with flexible URS, 609 (37.8\%) had a preoperative stent, of which 590 were with a JJ stent; 19 patients received another type of stent, and data were not available for 11 patients in the total cohort.

As expected, patients treated with a preoperative JJ stent, have more comorbidities, and lower preoperative physical fitness (ASA score). Also patients treated with a preoperative JJ stent more often had smaller stones in the proximal, mid or in multiple locations for ureteric stones and smaller stones in the lower pole for renal stones. An access sheath was used in $63(6 \%)$ and $377(5 \%)$ of the ureteric stone cases with and without a preoperative stent, respectively. For renal stones, an access sheath was used in 402 (66\%) with, and 719 (72\%) without a preoperative stent.

Figures 1 and 2 show the numbers of patients treated with a preoperative JJ stent per country for patients with ureteric stones and renal stones, respectively. The large majority of patients with ureteric stones were treated without a stent.
Table 2 Characteristics of participants treated with flexible URS for renal stones either with or without the use of a preoperative JJ stent. Number of patients ( $n$ ) for whom data were available indicated.

\begin{tabular}{|c|c|c|}
\hline Variable & $\begin{array}{l}\text { Patients with JJ } \\
\text { stent }(n=\mathbf{5 9 0})\end{array}$ & $\begin{array}{l}\text { Patients without JJ } \\
\text { stent }(n=1002)\end{array}$ \\
\hline \multicolumn{3}{|l|}{ Mean (sD) } \\
\hline Age, years & $51.7(15.1) ; n=590$ & $50.5(14.7) ; n=1002$ \\
\hline BMI, $\mathrm{kg} / \mathrm{m}^{2}$ & $28.3(7.4) ; n=488$ & $27.5(6.8) ; n=922$ \\
\hline \multicolumn{3}{|l|}{$N(\%)$} \\
\hline Female & 205 (34.7); $n=590$ & $447(44.6) ; n=1002$ \\
\hline \multicolumn{3}{|l|}{ Co-morbidity } \\
\hline DM & $76(13.1) ; n=579$ & $126(12.7) ; n=994$ \\
\hline CVD & $186(32.1) ; n=579$ & $317(32.0) ; n=992$ \\
\hline Prednisone & $11(1.9) ; n=577$ & $13(1.3) ; n=993$ \\
\hline Crohn's disease & $7(1.2) ; n=579$ & $13(1.3) ; n=993$ \\
\hline Anticoagulation & $50(8.7) ; n=577$ & $93(9.4) ; n=990$ \\
\hline ASA score & $n=498$ & $n=952$ \\
\hline I & $168(33.7)$ & $360(37.8)$ \\
\hline II & $250(50.2)$ & $424(44.5)$ \\
\hline III & $78(15.7)$ & $156(16.4)$ \\
\hline IV & $2(0.4)$ & $12(1.3)$ \\
\hline Academic centre, $n(\%)$ & $316(53.6) ; n=590$ & $462(46.1) ; n=1002$ \\
\hline High case-volume centre & $501(84.9) ; n=590$ & $785(78.3) ; n=1002$ \\
\hline Stone location, $n(\%)$ & $n=579$ & $n=979$ \\
\hline Renal pelvis & $113(19.5)$ & $207(21.1)$ \\
\hline Upper pole & $38(6.6)$ & $90(9.2)$ \\
\hline Mid pole & $43(7.4)$ & $77(7.9)$ \\
\hline Lower pole & $235(40.6)$ & $321(32.8)$ \\
\hline Multiple & $150(25.9)$ & $284(29.0)$ \\
\hline Stone size, $n(\%)$ & $n=542$ & $n=949$ \\
\hline$\leq 10 \mathrm{~mm}$ & $319(58.9)$ & $413(43.5)$ \\
\hline$>10 \mathrm{~mm}$ & $223(41.1)$ & $536(56.5)$ \\
\hline Postoperative nephron-drain & $4(0.7) ; n=590$ & $16(1.6) ; n=1001$ \\
\hline
\end{tabular}

$D M$, diabetes mellitus; CVD, cardiovascular disease; ${ }^{*}$ Defined as $>67$ cases per year

Among patients with ureteric stones, $>50 \%$ of the patients from Germany received a preoperative JJ stent, while for patients with renal stones the same applied to Chile,

Germany, Israel, Egypt, and China.

Tables 3 and 4 show the best prediction models for preoperative ureteric stent placement preceding ureteric and renal stone treatments. These models represent best prediction and include all variables that were of influence for the baseline probability of receiving a preoperative ureteric stent. For ureteric stones these variables were stone size, ASA score, BMI, antibiotic use, having a solitary kidney, age, anticoagulants use, Crohn's disease, hospital case volume, and previous stone treatment. For renal stones these predictor variables were gender, renal stone size, having a solitary kidney, and congenital abnormalities.

Table 5 shows descriptive information on the outcomes after stone treatment with or without a preoperative ureteric stent placement. These outcome variables are used in the second and third step of the IPWRA regression analysis.

Outcomes of (multivariate) IPWRA models for renal stone treatment are shown in Table 6A. This shows that a preoperative stent placement increased the SFR and operative duration, and there was also a trend for decreased 
Fig. 1 Number of patients with a JJ stent per country for patients with ureteric stones. Number of patients included per country shown. Only those countries with $>50$ patients included in the study are represented.

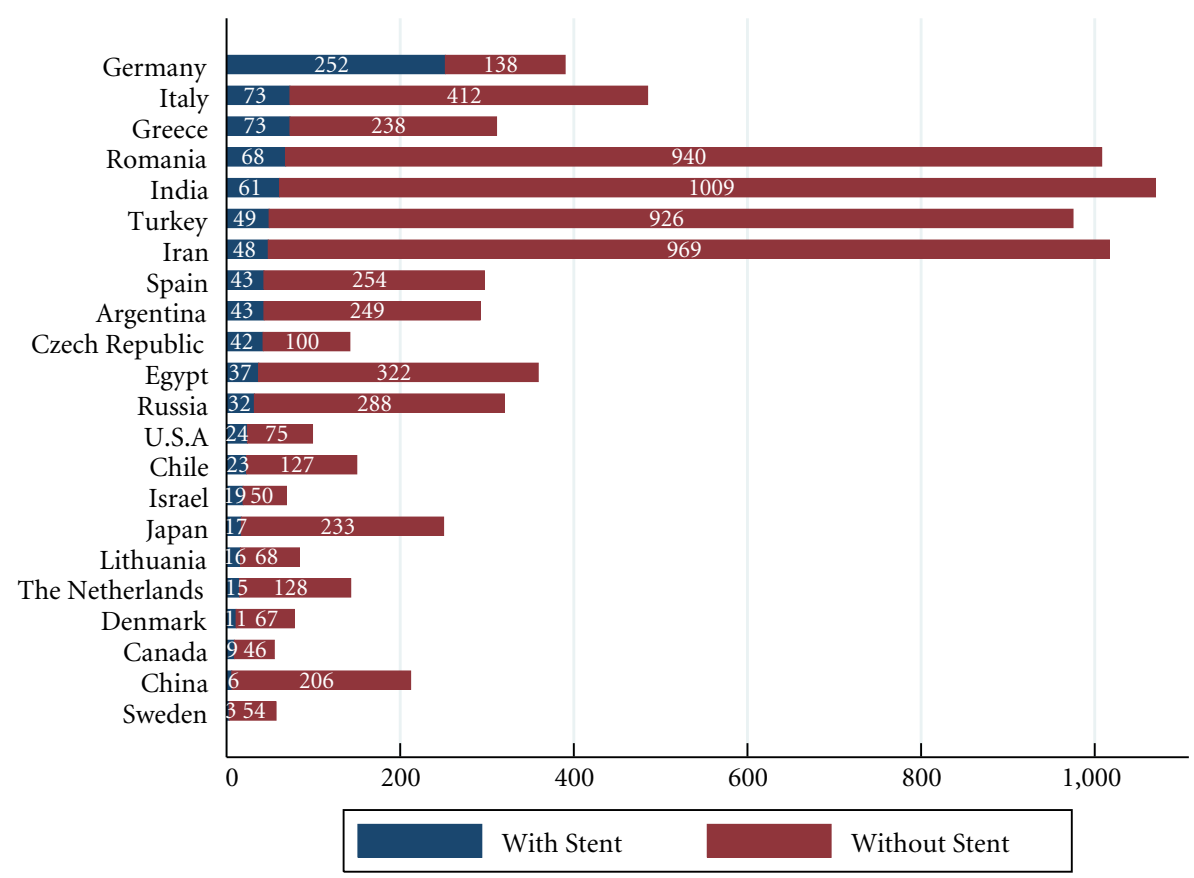

Fig. 2 Number of patients with a JJ stent per country for patients with renal stones. Number of patients included per country shown. Only those countries with $>10$ patients included in the study are represented.

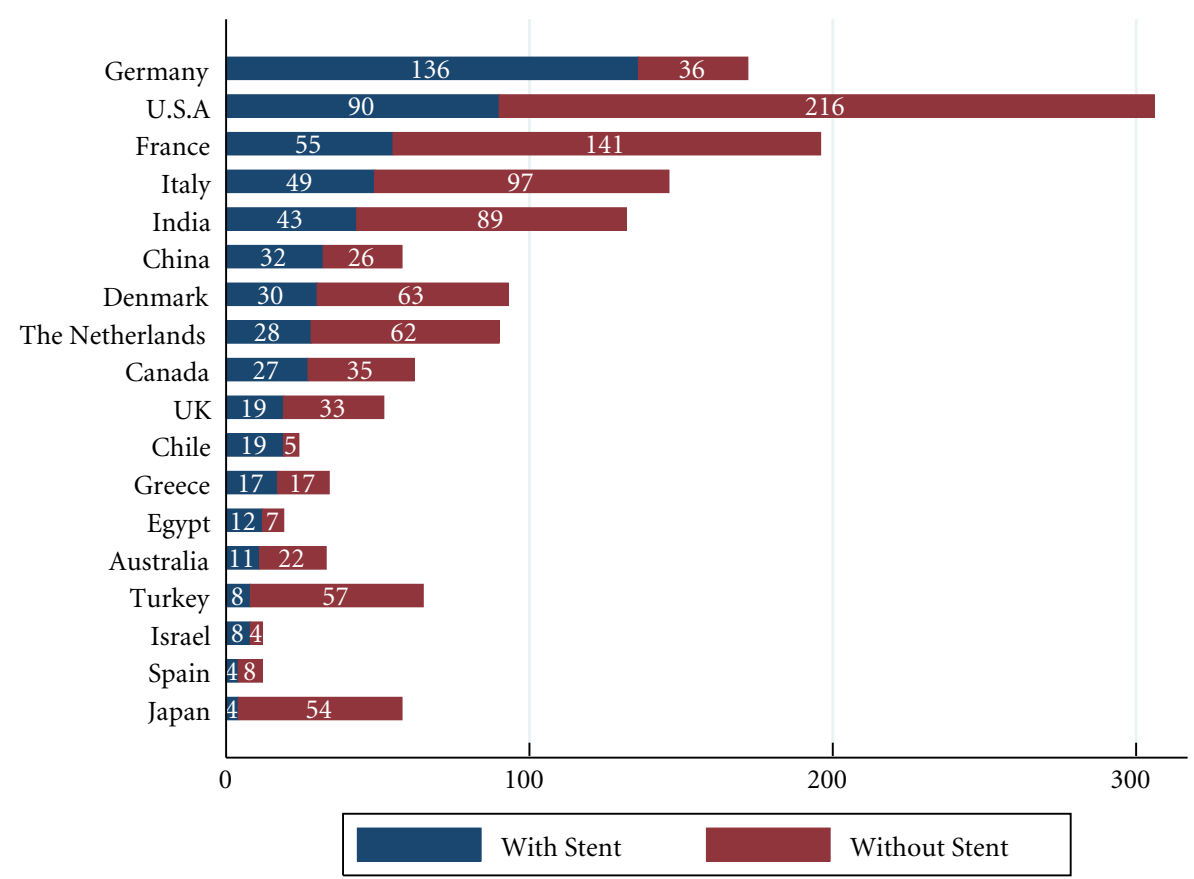

intraoperative complications but there was no relationship with LOHS and postoperative complications. Table 6B, representing the ureteric stone treatments, shows that a preoperative stent placement was associated with longer operative duration and decreased LOHS but there was no difference in SFRs and complications. 
Table 3 Prediction model for preoperative ureteric stent placement in those with ureteric stones. Odds represent the likelihood that a patient is treated with (yes) vs without a preoperative JJ stent placement (no). For example, the odds of 0.92 in the first row confirms the odds against a preoperative JJ stent placement with higher stone size.

\begin{tabular}{lllll|}
\hline $\begin{array}{l}\text { Preoperative ureteric } \\
\text { stent placement } \\
\text { 'Yes' vs 'No' }\end{array}$ & $\begin{array}{l}\text { Odds } \\
\text { ratio }\end{array}$ & $\begin{array}{c}\text { Standard } \\
\text { error }\end{array}$ & $\mathbf{9 5 \%} \mathbf{~ C l}$ \\
\hline Ureteric stone size & 0.92 & 0.01 & 0.90 & 0.94 \\
ASA & 1.38 & 0.09 & 1.22 & 1.57 \\
BMI & 1.03 & 0.01 & 1.01 & 1.04 \\
Antibiotics use & 0.65 & 0.08 & 0.51 & 0.82 \\
Solitary kidney & 1.63 & 0.30 & 1.14 & 2.34 \\
Age & 1.01 & 0.00 & 1.00 & 1.01 \\
Anticoagulants use & 1.33 & 0.21 & 0.97 & 1.82 \\
Crohn's disease & 2.60 & 1.33 & 0.95 & 7.09 \\
Case volume & 1.00 & 0.00 & 1.00 & 1.00 \\
Previous stone treatment & 0.86 & 0.08 & 0.72 & 1.03 \\
\hline
\end{tabular}

Table 4 Prediction model for preoperative ureteric stent placement in those with renal stones.

\begin{tabular}{lllll}
\hline $\begin{array}{l}\text { Preoperative ureteric } \\
\text { stent placement }\end{array}$ & $\begin{array}{c}\text { Odds } \\
\text { ratio }\end{array}$ & $\begin{array}{c}\text { Standard } \\
\text { error }\end{array}$ & \multicolumn{9}{c}{$\mathbf{9 5}$ CI } \\
\hline BMI & 1.02 & 0.01 & 1.00 & 1.04 \\
Gender & 0.67 & 0.08 & 0.53 & 0.85 \\
Renal stone size & 0.95 & 0.01 & 0.93 & 0.97 \\
Solitary kidney & 2.03 & 0.60 & 1.14 & 3.61 \\
Congenital abnormalities & 0.87 & 0.06 & 0.76 & 1.00 \\
\hline Gender = Female (1) over male (0). & & & &
\end{tabular}

Additionally, in Table 7 an overview of the nature of the intra- and postoperative complications is presented.

\section{Discussion}

The present report is based on observational data from the URS Global Study cohort and reveals that operative duration was significantly longer in ureteric stone treatment with URS in conjunction with a preoperative JJ stent, whereas the LOHS was shorter and there were no differences in complication rates or SFRs. For renal stones, the operative duration was significantly longer and SFR higher with preoperative JJ stenting and there was also a trend for decreased intraoperative complications.
Possible reasons for JJ stent placement include obstructing ureteric stone, upper tract pyelonephritis before stone surgery, or pain complaints. Another reason may be to facilitate the insertion of an access sheath, or a failed previous URS attempt because of a tight ureter. Also, JJ stents were more often placed in men than women but the probable reasoning is unclear, as the justification for preoperative stent use was not captured in the database. Consequently, we could only use information on access sheath use, and previous stone treatment as predictor variables, assuming that we would cover the reasons for placing a JJ stent. In the present study, several factors were revealed concerning the decision to place a preoperative JJ stent in centres worldwide. Overall, the use of a JJ stent was low in patients with ureteric stones at $11.9 \%$ but somewhat higher in those with renal stones at $36.4 \%$. In concordance with current guidelines, patients with higher comorbidity and ASA scores were more often treated with a JJ stent. Academic centres were more reluctant to use a stent, as were high case-volume centres among patients with ureteric stones treated with semi-rigid URS, whilst among patients with renal stones treated by flexible URS the JJ stent was less often used in low case-volume centres.

Observational studies, as currently used, have advantages, as they are not limited by many exclusion criteria and patient selection. Also, every physician can follow local procedures and personal preferences and still include patients. As a result they provide valuable information on day-to-day practice and reflect more than just 'the perfect patient' including those with comorbidities. Subsequently, the present study may support the decision-making process in everyday practice. Nevertheless, the observational nature of this study is at the same time its strongest and weakest characteristic. Reflecting clinical reality worldwide is of great interest but is limited by the impossibility to perform analysis such as used in a randomised controlled trial setting. We therefore chose to analyse the research questions using the IPWRA. IPWRA weights patients who are under-represented or overrepresented with a higher and lower weight, respectively. The prediction models for ureteric (Table 3) and renal (Table 4) stones show that certain baseline characteristics statistically influence the probability of being treated with a preoperative ureteric stent. Outcome models presented in Table 6 are

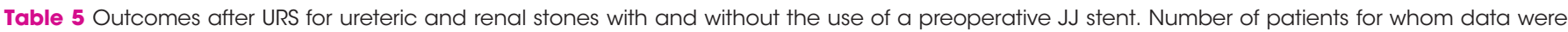
available indicated $(n)$.

\begin{tabular}{|c|c|c|c|c|}
\hline & \multicolumn{2}{|c|}{ Ureteric stones } & \multicolumn{2}{|c|}{ Renal stones } \\
\hline & With stent & Without stent & With stent & Without stent \\
\hline SFR, \% & $91.1 ; n=1035$ & $91.2 ; n=7088$ & $79.6 ; n=594$ & $72.9 ; n=959$ \\
\hline Mean (SD) operative duration, min & $44.1(28.3) ; n=1030$ & $40.6(24.1) ; n=7028$ & $75.0(42.9) ; n=583$ & $73.3(41.6) ; n=967$ \\
\hline Intraoperative complication rate, $\%$ & $5.7 ; n=1021$ & $3.2 ; n=7040$ & $4.5 ; n=604$ & $6.6 ; n=987$ \\
\hline Mean (SD) LOHS, days & $3.6(21.9) ; n=1035$ & $3.2(23.0) ; n=7115$ & $4.1(36.3) ; n=608$ & $2.3(15.3) ; n=998$ \\
\hline Postoperative complication rate, \% & $2.6 ; n=1033$ & $3.2 ; n=7100$ & $10.6 ; n=601$ & $13.2 ; n=993$ \\
\hline
\end{tabular}


Table 6 Examining outcomes after stone treatment with or without the use of a preoperative stent using IPWRA.

\begin{tabular}{|c|c|c|c|}
\hline Outcome & Stent & Coefficient & $\mathbf{P}$ \\
\hline \multicolumn{4}{|l|}{ A. Renal stones } \\
\hline \multirow[t]{3}{*}{ Stone free } & No & 0.73 & 0.00 \\
\hline & Yes & 0.77 & 0.00 \\
\hline & Percentage & 0.06 & $0.05^{*}$ \\
\hline \multirow[t]{3}{*}{ Intraoperative complications } & No & 0.07 & 0.00 \\
\hline & Yes & 0.04 & 0.00 \\
\hline & Percentage & -0.33 & $0.06^{*}$ \\
\hline \multirow[t]{3}{*}{ Postoperative complications } & No & 0.14 & 0.00 \\
\hline & Yes & 0.11 & 0.00 \\
\hline & Percentage & -0.21 & 0.12 \\
\hline \multirow[t]{3}{*}{ Operative duration ${ }^{\dagger}$} & No & 71.61 & 0.00 \\
\hline & Yes & 81.60 & 0.00 \\
\hline & Percentage & 0.14 & $0.00^{* *}$ \\
\hline \multirow[t]{3}{*}{ LOHS } & No & 2.43 & 0.00 \\
\hline & Yes & 4.57 & 0.02 \\
\hline & Percentage & 0.88 & 0.37 \\
\hline \multicolumn{4}{|l|}{ B. Ureteric stones } \\
\hline \multirow[t]{3}{*}{ Stone free } & No & 0.91 & 0.00 \\
\hline & Yes & 0.91 & 0.00 \\
\hline & Percentage & 0.00 & 0.93 \\
\hline \multirow[t]{3}{*}{ Intraoperative complications } & No & 0.05 & 0.00 \\
\hline & Yes & 0.06 & 0.00 \\
\hline & Percentage & 0.21 & 0.27 \\
\hline \multirow[t]{3}{*}{ Postoperative complications } & No & 0.04 & 0.00 \\
\hline & Yes & 0.03 & 0.00 \\
\hline & Percentage & -0.29 & 0.11 \\
\hline \multirow[t]{3}{*}{ Operative duration ${ }^{\dagger}$} & No & 37.06 & 0.00 \\
\hline & Yes & 44.73 & 0.00 \\
\hline & Percentage & 0.21 & $0.00^{* *}$ \\
\hline \multirow[t]{3}{*}{ LOHS $^{*}$} & No & 3.35 & 0.00 \\
\hline & Yes & 2.46 & 0.00 \\
\hline & Percentage & -0.27 & $0.04^{* x}$ \\
\hline
\end{tabular}

${ }^{*}$ Defined as significant using a threshold of $P=0.10 ;{ }^{* *}$ Defined as highly significant using a threshold of $P=0.05 ;{ }^{\dagger}$ Operative duration in minutes; ${ }^{\star} \mathrm{LOHS}$ in days.

weighted for these variables, meaning that outcomes are not explained by these baseline characteristics.

Another limitation of the study is the data design. The database is ordered by URS procedure and not by patient. In the case that a patient is treated for both a ureteric and renal stone at the same time, the patient is classified as 'renal treatment'. If a patient is retreated (for a renal or ureter stone procedure), the second procedure is entered in the database as a new case. The drawback is that patients with repeated URS treatments cannot be linked. Thus, besides using the 're-treatment variable' no separate or sub-analysis could be performed for patients that have been included in the database for more than one procedure.

The present study shows that the use of a preoperative JJ stent increased the likelihood of being stone free in patients with renal stones. This finding is in concordance with previous studies. A case-matched study of 143 patients who were preoperatively stented and an equivalent number who were not preoperatively stented was reported by Netsch et al. [7]. Overall, their SFR were significantly higher in stented patients at $95.1 \%$ vs $86.7 \%(P \leq 0.013)$; however, there was no significant difference with ureteric stones sized $<5 \mathrm{~mm}$ or for
Table 7 Type of intra- and postoperative complications per procedure.

\begin{tabular}{lcc|}
\hline Complication & $\begin{array}{c}\text { Ureteric stone } \\
\text { treatment, } \boldsymbol{n} \text { (\%) } \\
\text { (total } \mathbf{8} \mathbf{1 8 9} \text { cases) }\end{array}$ & $\begin{array}{c}\text { Renal stone } \\
\text { treatment, } \boldsymbol{n} \text { (\%) } \\
\text { (total } \mathbf{1} \text { 622 cases) }\end{array}$ \\
\hline $\begin{array}{l}\text { Intraoperative } \\
\text { Avulsion }\end{array}$ & $10(0.12)$ & None \\
Converted & $6(0.07)$ & $2(0.12)$ \\
Perforation & $87(1.06)$ & $19(1.18)$ \\
Bleeding & $93(1.14)$ & $37(2.29)$ \\
Failed & $134(1.64)$ & $24(1.48)$ \\
Other & $99(1.21)$ & $23(1.42)$ \\
Uneventful cases & $7707(94.16)$ & $1511(93.44)$ \\
Postoperative & & \\
Bleeding & $31(0.38)$ & $11(0.68)$ \\
Fever & $111(1.36)$ & $54(3.33)$ \\
UTI & $55(0.67)$ & $36(2.22)$ \\
Bladder cramps & $27(0.33)$ & $15(0.92)$ \\
Lung embolism & $1(0.01)$ & $1(0.06)$ \\
Deep venous & None & None \\
thrombosis & $1(0.01)$ & $1(0.06)$ \\
CVA/TIA & $16(0.20)$ & $14(0.86)$ \\
Sepsis & $2(0.02)$ & $2(0.12)$ \\
Acute abdomen & None & None \\
Acute myocardial & & $53(3.27)$ \\
infarction & $44(0.54)$ & \\
Other & & \\
\hline
\end{tabular}

CVA, cerebrovascular accident; TIA, transient ischaemic attack.

renal stones in general. A study by Lumma et al. [5] reported SFRs of $72.2 \%$ and $59.4 \%$ in 550 patients with ureteric or renal stones treated with or without a preoperative JJ stent, respectively. Their rate of stent placement was high, being $88.4 \%$ of all URS procedures. Rubenstein et al. [6] reported significantly higher SFRs with stented patients in a series of 90 patients with renal or ureteric stones at $67 \%$ vs $47 \%(P<0.05)$. Most patients received stents due to technical considerations during surgery (47\%) or infection (37\%). Shields et al. [8] also reported higher SFRs with stenting in a series of 259 patients with ureteric and renal stones but the difference was not significant. This might be explained by the high SFRs in ureteric stone treatment without preoperative stenting.

The present study also showed a trend for lower intraoperative complication rates in patients with renal stones treated with a preoperative stent. In contrast, no difference in the probability of intraoperative complications was reported in patients with ureteric stones. Nor was any difference found for postoperative complications after treating ureteric and renal stones. These findings are partly in contrast with those of Rubenstein et al. [6], who reported no difference in complications rates between stented and unstented patients (5.6\% vs $7.6 \%)$. In their matched case series, Netsch et al. [7] also reported no difference in complications rates with preoperative stenting, while Lumma et al. [5] reported a lower rate of complications in stented patients; minor complications: $4.7 \%$ vs $9.4 \%$ and major complications: $0.6 \%$ vs $1.6 \%$.

The present study also found that operative durations were longer in patients with ureteric or renal stones treated with a 
preoperative JJ stent, although the eventual LOHS was shortened in patients treated for ureteric stones. As the CROES study is global, it consists of many centres with different patterns in clinical practice. In some countries procedures were performed in an ambulatory setting; however, in many others regular admission takes some days. Previous studies by Netsch et al. [7] and Lumma et al. [5] also reported longer operative durations in stented patients. Despite differences in clinical practice, one previously suggested possibility is that operative duration is lengthened due to the extraction of the stent before URS stone treatment, although it is doubtful whether the differences of 8 and 10 min in renal and ureteric stone treatment, respectively in the present study can be fully explained by extraction only. It is feasible that other characteristics not captured in the database, such as reason for stent placement and time from stent placement until procedure, might influence operative duration. A shorter total LOHS after the procedure in stented patients is a new finding that has not been described previously. It might be that the dilatation resulting from the preoperative ureteric stent results in lower stone retention or bacterial infection, which might lengthen hospital stay.

In conclusion, the use of a JJ stent in ureteric stone treatment did not result in higher SFRs or lower complications and the operative duration was longer, but the LOHS was shorter. For renal stones, using a preoperative JJ stent increased SFRs and there was a trend for decreased intraoperative complications, but operative durations were longer.

\section{Acknowledgments}

The URS Global Study was supported by an unrestricted educational grant from Boston Scientific. Dr Nienke Wijnstok provided statistical support for this manuscript.

\section{Conflict of interest}

No competing financial interests exist.

\section{References}

1 Nabi G, Downey P, Keeley F, Watson G, McClinton S. Extra-corporeal shock wave lithotripsy (ESWL) versus ureteroscopic management for ureteric calculi. Cochrane Database Syst Rev 2007; 1: CD006029

2 Matlaga BR, Jansen JP, Meckley LM, Byrne TW, Lingeman JE. Treatment of ureteral and renal stones: a systematic review and meta-analysis of randomized, controlled trials. J Urol 2012; 188: 130-7

3 Türk C, Knoll T, Petrik A, Sarica K, Straub M, Seitz C. Guidelines on Urolithiasis. European Association of Urology, 2012. Available at: http:// uroweb.org/wp-content/uploads/20_Urolithiasis_LR-March-13-2012.pdf. Accessed August 2015

4 Hubert KC, Palmer JS. Passive dilation by ureteral stenting before ureteroscopy: eliminating the need for active dilation. J Urol 2005; 174: 1079-80

5 Lumma PP, Schneider P, Strauss A et al. Impact of ureteral stenting prior to ureterorenoscopy on stone-free rates and complications. World J Urol 2013; 31: 855-9

6 Rubenstein RA, Zhao LC, Loeb S, Shore DM, Nadler RB. Prestenting improves ureteroscopic stone-free rates. J Endourol 2007; 21: 1277-80

7 Netsch C, Knipper S, Bach T, Herrmann TR, Gross AJ. Impact of preoperative ureteral stenting on stone-free rates of ureteroscopy for nephroureterolithiasis: a matched-paired analysis of 286 patients. Urology 2012; 80: 1214-9

8 Shields JM, Bird VG, Graves R, Gómez-Marín O. Impact of preoperative ureteral stenting on outcome of ureteroscopic treatment for urinary lithiasis. J Urol 2009; 182: 2768-74

9 De la Rosette J, Denstedt J, Geavlete P et al. The Clinical Research Office of the Endourological Society Ureteroscopy Global Study: indications, complications, and outcomes in 11885 patients. J Endourol 2014; 28: 131-9

Correspondence: Jean de la Rosette, Department of Urology, AMC University Hospital, Meibergdreef 9, 1105 AZ

Amsterdam Z-O, The Netherlands.

e-mail: j.j.delarosette@amc.uva.nl

Abbreviations: ASA, American Society of Anaesthesiologists; BMI, body mass index; CROES, Clinical Research Office of the Endourology Society; EAU, European Association of Urology; IPWRA, inverse-probability-weighted regression adjustment; IQR, interquartile range; IRB, Institutional Review Board; LOHS, length of hospital stay; SFR, stone-free rate; URS, ureteroscopy. 